\title{
Efeito do BAP no cultivo in vitro de Ocimum selloi Benth.
}

MONFORT, L.E.F.*; PINTO, J.E.B.P.; BERTOLUCCI, S.K.V.; ROSSI, Z.T.T.; SANTOS, F.M.

Universidade Federal de Lavras, Caixa Postal 3037, CEP: 37200-000, Lavras-Brasil *lucilaagro@yahoo.com.br

\begin{abstract}
RESUMO: Visando promover a proliferação de brotações em segmentos apicais e nodais de Ocimum selloi em diferentes concentrações de BAP, plantas jovens de 60 dias serviram de doadoras de segmentos apicais e nodais. Os segmentos foram inoculados em meio MS preparado com a metade da concentração dos sais, e acrescido de 1,5\% de sacarose e diferentes concentrações de BAP. O experimento foi conduzido no delineamento fatorial, $3 \times 4$, sendo 3 as posições dos segmentos de $O$. selloi (segmento apical, primeiro e segundo segmentos nodais) e 4 concentrações de BAP ( 0 - controle; $2 ; 4$ e $\left.6 \mathrm{mg} \mathrm{L}^{-1}\right)$. Aos 30 dias, foram avaliados o número, comprimento e biomassa fresca e seca de brotos e raízes. Os primeiros e segundos segmentos apresentaram melhores resultados na indução de brotos de 0 . selloi, 7 e 8 brotos/explante, nas diferentes concentrações de BAP; porém, não houve formação de raízes na presença da citocinina. Nas condições testadas, recomenda-se o uso do primeiro e segundo segmento nodal suplementando o meio de cultivo com BAP para a proliferação in vitro de brotações de $O$. selloi.
\end{abstract}

Palavras-chave: atroveran, planta medicinal, micropropagação, benzilaminopurina

ABSTRACT: Effect of BAP on in vitro culture of Ocimum selloi Benth. The present study was undertaken to develop the proliferation of sprouts in apical and nodal segments of Ocimum selloi with different BAP levels. Young plants aged 60 days were used as donors of nodal and apical segments. The segments were inoculated in MS medium at half the concentration of salts supplemented with $1.5 \%$ of sucrose and different BAP levels. The experiment was in $3 \times 4$ factorial arrangement, 3 positions of $O$. selloi segments (apical segment; first and second nodal segment) and 3 BAP levels ( 0 - control; 2; 4 and $\left.6 \mathrm{mg} \mathrm{L}^{-1}\right)$. After 30 days, the number, the length, and the fresh and dry biomass of sprouts and roots were evaluated. The first and the second segments showed better results in inducing $O$. selloi sprouts, 7 and 8 sprouts/explant, at the different BAP levels, but there was not root formation in the presence of the cytokinin. Under the tested conditions, use of the first and the second nodal segments is recommended in addition to supplementing the culture medium with BAP for in vitro proliferation of $O$. selloi sprouts.

Key words: "atroveran", medicinal plant, micropropagation, benzylaminopurine

\section{INTRODUÇÃO}

Ocimum selloi Benth. (Lamiaceae) é popularmente conhecido como atroveran, alfavaca, elixir-paregórico, anis-do-campo, erva-doce-silvestre, alfavaca-do-mato, hortelã-brava. Estudos de Franca et al. (2008) demonstraram atividade antiespasmódica e antidiarréica dose-dependente do óleo essencial de $O$. selloi em ratos Swiis machos. Os usos populares alegados a esta planta são para o tratamento de má digestão, gastrite, vômitos, tosse e bronquite. Topicamente, o O. selloi é empregado para aliviar dores nas pernas. Além do uso medicinal, algumas espécies do gênero Ocimum são utilizadas também como tempero no Brasil (Lorenzi \& Matos, 2002).

A micropropagação é um dos mais promissores métodos para assegurar o uso sustentável de recursos vegetais. Muitas plantas medicinais já são multiplicadas in vitro, tais como Melissa officinalis (Reis et al., 2009), Ananas erectifolius (Pereira et al., 2008), Eremanthus erythropappus (Rosal et al., 2007), Lychnophora pinaster (Souza et al., 2007) e Jatropha elliptica (Campos et al., 2007). Em se tratando de plantas medicinais, onde a qualidade do material genético e a homogeneidade das plantas são fatores determinantes à qualidade, a micropropagação tem demonstrado excelentes resultados.

A indução de brotações in vitro ocorre pelo desequilíbrio hormonal induzido por concentração

Recebido para publicação em 02/12/2009

Aceito para publicação em 02/02/2012

Rev. Bras. PI. Med., Botucatu, v.14, n.3, p.458-463, 2012. 
adequada e balanceada de reguladores vegetais adicionadas ao meio, como a citocinina, a qual é muito favorável na fase de multiplicação in vitro. As citocininas estimulam a maior produção de partes aéreas das brotações até determinada concentração, a partir da qual, ocorre diminuição da altura em virtude de possível efeito fitotóxico da citocinina (Reis et al., 2008).

Amaral et al. (2007) estudando o efeito de concentrações de ANA e BAP e da posição dos explantes na indução de organogênese in vitro em segmentos caulinares internodais de $O$. selloi, verificaram que o primeiro, segundo e terceiro segmentos caulinares internodais apresentaram, em meio de cultivo suplementado com $1,00 \mathrm{mg} \mathrm{L}^{-1} \mathrm{de}$ ANA e $0,25 \mathrm{mg} \mathrm{L}^{-1}$ de BAP, frequência de calogênese de 60,50 e $60 \%$, respectivamente. O primeiro, segundo, e terceiro segmento caulinar internodal apresentaram, respectivamente, frequência de organogênese de $93,33 \%, 73,33 \%$ e $73,33 \%$, média de órgãos produzidos de 2,80, 1,80 e 1,80, e eficiência de organogênese de 2,60, 1,32 e 1,32 em meio de cultivo suplementado com $0,10 \mathrm{mg} \mathrm{L}^{-1}$ de ANAe 1,00 $\mathrm{mg} \mathrm{L}^{-1}$ de BAP.

Tendo em vista o desenvolvimento de um protocolo de micropropagação, objetivou-se avaliar a indução de brotações em segmentos apicais e nodais de $O$. selloi sob diferentes concentrações de BAP.

\section{MATERIAL E MÉTODO}

O experimento foi realizado no Laboratório de Cultura de Tecidos e Plantas Medicinais da Universidade Federal de Lavras-UFLA. Plantas jovens de $O$. selloi com 60 dias, cultivadas em casa de vegetação, serviram de doadoras de segmentos apicais e nodais, sendo os nodais obtidos do primeiro e do segundo segmento abaixo do apical.

A exsicata da espécie está depositada no herbário ESAL, no Departamento de Biologia da UFLA, sob o registro № 7474 .

Os segmentos foram cortados com o auxílio de lâmina e lavados abundantemente com água corrente e sabão neutro. Em seguida foram imersos em solução de hipoclorito de sódio comercial a $50 \%$ e mantidos em agitação constante por 15 minutos. $\mathrm{Na}$ sequência, os segmentos foram lavados cinco vezes em água destilada sob capela de fluxo laminar e autoclavada.

Após a assepsia, segmentos com tamanhos de cerca de $1 \mathrm{~cm}$ foram inoculados em tubos de ensaio contendo $10 \mathrm{~mL}$ de meio de cultura MS (Murashige \& Skoog, 1962), na concentração de 50\% dos sais, suplementado com $1,5 \%$ de sacarose e 4 concentrações de BAP ( 0 - controle; 2 ; 4 e $\left.6 \mathrm{mg} \mathrm{L}^{-1}\right)$. O meio de cultura foi solidificado com $0,6 \%$ de ágar, ajustado para $\mathrm{pH} 5,7 \pm 0,1$, e autoclavado por 20 minutos a $120^{\circ} \mathrm{C}$, sob $1 \mathrm{~atm}$. Após a inoculação os tubos foram fechados com tampas plásticas e vedados com parafilme. Os tubos foram mantidos em sala de crescimento com fotoperíodo de 16 horas luz/ 8 horas escuro, sob intensidade luminosa de $25 \mu \mathrm{mol}$ $\mathrm{m}^{-2} \mathrm{~s}^{-1}$, à temperatura de $26 \pm 0,1^{\circ} \mathrm{C}$.

O experimento foi conduzido de forma fatorial $3 \times 4$, sendo 3 as posições dos segmentos (apical; 1 o e 2 o segmentos) e 4 concentrações de BAP $(0 ; 2$; 4 e $\left.6 \mathrm{mg} \mathrm{L}^{-1}\right)$, totalizando 12 tratamentos. Foi utilizado o delineamento inteiramente casualizado com 4 repetições, sendo 5 tubos por repetição e 1 explante por tubo.

Aos 30 dias foram avaliados o número, a altura $(\mathrm{cm})$, e as biomassas fresca e seca dos brotos $(\mathrm{mg})$, bem como o número, comprimento $(\mathrm{cm})$ e biomassas fresca e seca das raízes $(\mathrm{mg})$.

A altura dos brotos e o comprimento das raízes foram determinados com o auxílio de régua. Para a altura, a medição foi feita desde a base da brotação até a gema apical. Para a determinação da biomassa seca, os brotos e as raízes foram colocados em sacos de papel kraft e acondicionados em estufa de circulação forçada de $a r, a 60^{\circ} \mathrm{C}$, por 5 dias. Após esse período, o material vegetal foi mensurado em balança de precisão.

A análise estatística dos dados foi realizada pelo software Sisvar ${ }^{\circledR}$, versão 5.0 (Ferreira, 2007). Os dados obtidos foram submetidos à ANOVA, pelo teste $F(p<0,05)$. Para comparação dos segmentos foi utilizado o teste de Scott-Knott $(p<0,05)$. A comparação das concentrações de BAP foi realizada por meio da análise de regressão polinomial.

\section{RESULTADO E DISCUSSÃO}

A interação foi significativa para as variáveis: número, altura e biomassa fresca das brotações, e também para o número e comprimento de raízes. Para biomassa seca de brotações os efeitos da posição do segmento e da concentração de BAP foram significativos apenas quando analisados separadamente; o mesmo ocorreu para a biomassa fresca e seca de raízes.

Os resultados da capacidade de regeneração avaliada pelo número de brotações na interação "posição do segmento e concentração de BAP" estão apresentados na Figura 1.

O segmento apical não induziu diferença estatística para o número de brotos nas concentrações de BAP. Esse resultado pode ser observado pelo comportamento linear constante para o segmento apical na Figura 1. No entanto, os primeiros e os segundos segmentos induziram efeitos quadráticos. A taxa de proliferação de brotos/explante foi similar para os primeiros e os segundos segmentos nodais aumentando até o ponto máximo, e havendo

Rev. Bras. PI. Med., Botucatu, v.14, n.3, p.458-463, 2012. 


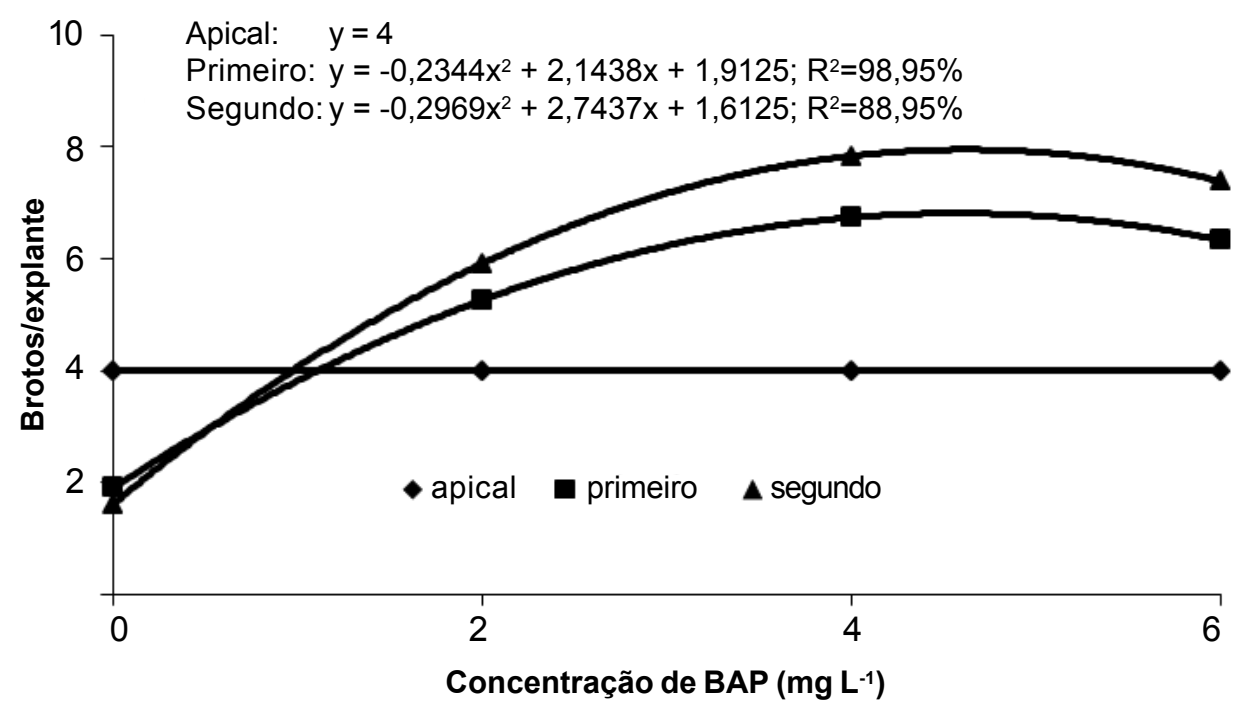

FIGURA 1. Número de brotos por explante de Ocimum selloi submetidas a diferentes concentrações de BAP, aos 30 dias de cultivo in vitro em meio MS.

decréscimo na regeneração após esse ponto. 0 primeiro segmento produziu um número máximo estimado de 7 brotos/explante na concentração de $4,57 \mathrm{mg} \mathrm{L}^{-1}$ de BAP e, o segundo segmento, foi de 8 brotos/explante na concentração de $4,62 \mathrm{mg} \mathrm{L}^{-1}$ de BAP. Para ambos os segmentos, a ausência do regulador de crescimento não induziu a proliferação de brotos. Esse resultado indica que há diferenças no desenvolvimento dos segmentos de O. selloi, de acordo com a posição na planta, pois responderam diferentemente ao processo morfogenético in vitro. $A$ posição da excisão do explante na planta matriz tem mostrado diferenças na capacidade de regeneração em Mentha spicata, M. gracilis e M. piperita (Poovaiah et al., 2006a, b; Wang et al., 2009). Este último autor demonstrou que o segundo segmento internodal produziu o maior número de brotos/explante em $M$. piperita.

O balanço, a interação, e a concentração endógena de fito hormônios do explante determinam o processo morfogenético in vitro. Embora auxinas e citocininas sejam normalmente requeridas para o crescimento ou morfogênese, as auxinas podem inibir o acúmulo de citocininas, enquanto as citocininas podem inibir pelo menos alguma ação das auxinas. Os segmentos apicais são fontes de fitohormônios do grupo das auxinas, relacionados com a dominância apical. Portanto, mesmo o suplemento da citocinina não foi suficiente para alterar o balanço hormonal e induzir maior proliferação de brotações. Entretanto, quando da retirada do primeiro e do segundo segmentos nodais, houve a quebra da dominância apical que, somada a suplementação da citocinina, promoveu maior proliferação das brotações, provavelmente devido a desbalanço hormonal em favor do grupo das citocininas.

Na propagação in vitro de Ocimum basilicum L., Dode et al. (2003) observaram que a maior eficiência na formação de brotos foi obtida utilizando $5 \mathrm{mg} \mathrm{L}^{-1}$ BAP e 0,2 $\mathrm{mg} \mathrm{L}^{-1}$ ANA. Vicente et al. (2009), trabalhando com Vernonia condensata, constataram que a concentração de $1,0 \mathrm{mg} \mathrm{L}^{-1}$ de BAP foi a que proporcionou a melhor resposta com relação ao número de brotos por explantes. Brum et al. (2002) demonstraram que o efeito benéfico do BAP na multiplicação das brotações pode estar relacionado com a influência desse regulador na divisão celular e na quebra de dormência das gemas axilares, até então inibidas pela dominância apical.

Já para o crescimento dos brotos, a maior altura ocorreu na ausência de BAP em todos os segmentos avaliados, embora as brotações obtidas do segmento apical tenham altura significativamente menor em relação aos primeiros e segundos segmentos (Figura 2).

As brotações obtidas a partir do segmento apical apresentaram decréscimo linear, com diminuição de $0,05 \mathrm{~cm}$ na altura a cada aumento de 2,0 mg. $\mathrm{L}^{-1}$ de BAP. Os primeiros e os segundos segmentos nodais apresentaram comportamento quadrático, tendo como ponto de mínimo 0,66 e 0,64 $\mathrm{cm}$, nas concentrações de 4,89 e 5,49 $\mathrm{mg} \mathrm{L}^{-1}$ de BAP, respectivamente. Os resultados corroboram os dados da literatura de que a citocinina induz divisão celular e proliferação de brotos, e que, dependendo da sua concentração, pode inibir o efeito da auxina que induz o alongamento das células vegetais (Taiz \& Zeiger, 2004). Pérez-Tornero et al. (2000) observaram que doses crescentes de citocininas inibiram o alongamento das brotações em Prunaceae. Conforme 


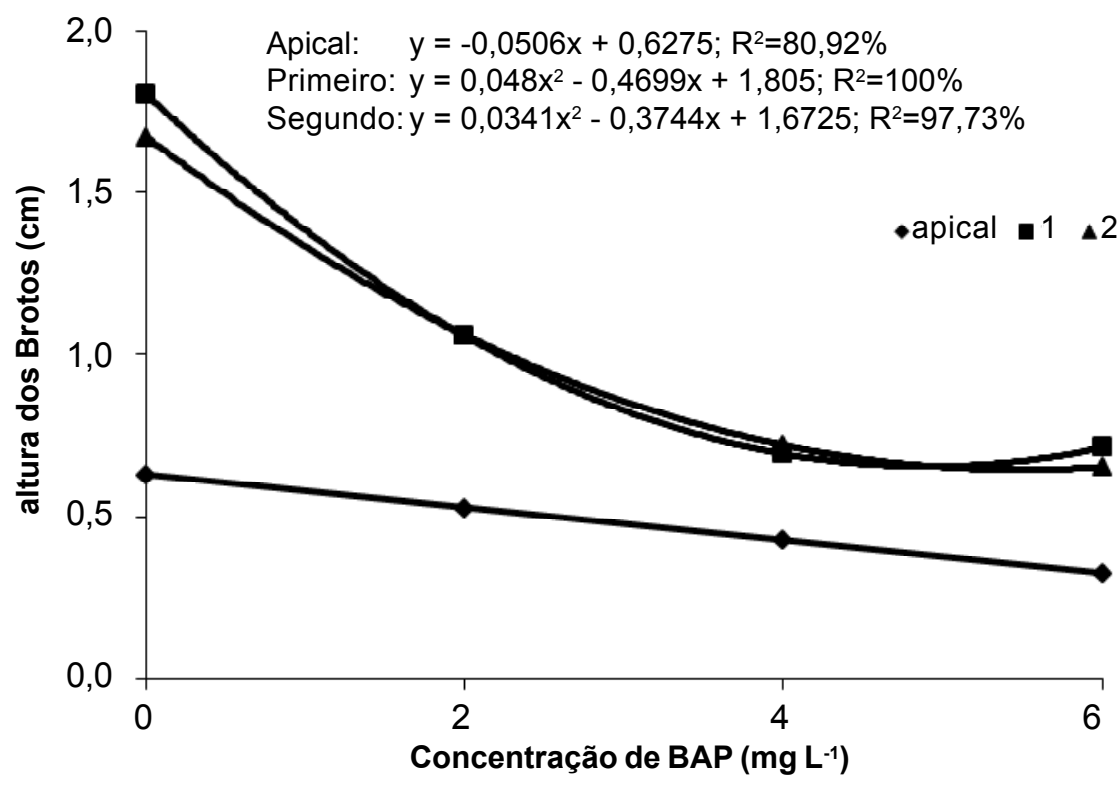

FIGURA 2. Altura dos brotos de segmento apical e nodal de Ocimum selloi submetidas a diferentes concentrações de BAP, aos 30 dias de cultivo in vitro em meio MS.

Leshem et al. (1988) o uso de citocininas em níveis elevados pode ser tóxico, pois leva à formação de rosetas e inibe o alongamento dos brotos. É provável que os segmentos caulinares acumulem concentrações diferentes destes reguladores de crescimento vegetal nas diferentes posições, resultando em diferentes respostas de desenvolvimento.

Verificou-se efeito quadrático das doses de
BAP sobre a biomassa seca dos brotos obtidos a partir de todos os tipos de segmentos testados (Figura 3). Maiores concentrações de BAP tenderam reduzir a biomassa fresca das brotações. Os segmentos apicais, primeiro, e segundo, apresentaram as biomassas máximas de 48,91, 89,50 e 112,02 mg nas concentrações de 4,19, 4,31 e 3,34 $\mathrm{mg} \mathrm{L}^{-1}$ de BAP, respectivamente.

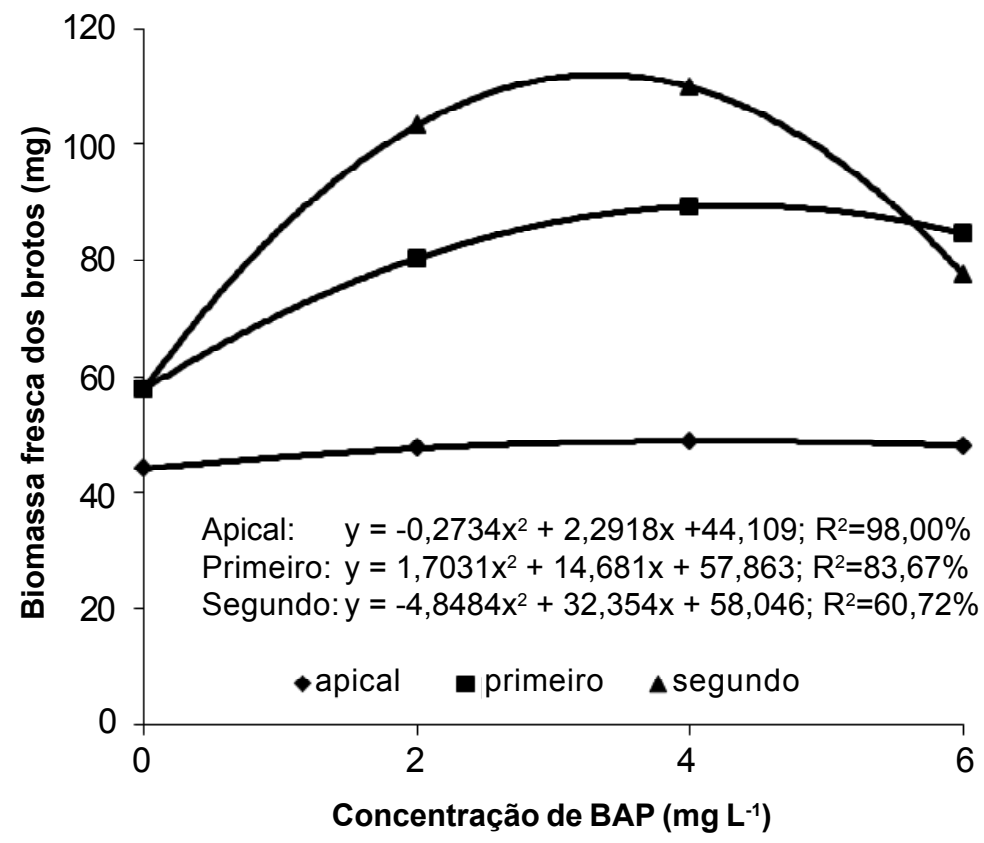

FIGURA 3. Biomassa fresca dos brotos de segmento apical e nodal de Ocimum selloi submetidas a diferentes concentrações de BAP, aos 30 dias de cultivo in vitro em meio MS. 
Não se verificou interação entre o tipo de segmento e as doses de BAP em relação a biomassa seca das brotações. Com relação à posição do segmento, o segundo segmento nodal forneceu melhor resposta, seguido do primeiro, e este, seguido do apical (Tabela 1).

TABELA 1. Valores médios da biomassa seca dos brotos nos diferentes segmentos de Ocimum selloi.

\begin{tabular}{cc}
\hline Segmentos & Biomassa seca dos brotos $(\mathbf{m g})$ \\
\hline Apical & $4,2 \mathrm{C}$ \\
$1 ㅇ$ & $6,4 \mathrm{~b}$ \\
$2 \circ$ & $8,7 \mathrm{a}$
\end{tabular}

Médias seguidas da mesma letra não diferem entre $s i, p<0,05$, teste de Scott-Knott.
A análise de regressão demonstrou efeito cúbico das concentrações de BAP sobre a biomassa seca dos brotos (Figura 4). A derivada da equação mostrou biomassa seca máxima de 8,62 mg em 4,67 $\mathrm{mg} \mathrm{L}^{-1}$ de BAP e biomassa seca mínima de $4,45 \mathrm{mg}$ em 1,23 $\mathrm{mg} \mathrm{L}^{-1}$ de BAP. A ausência de BAP proporcionou maior altura de brotos, possibilitando maior produção de biomassa. O acréscimo da citocinina ao meio de cultura fez com que a altura dos brotos tendesse a diminuir, porém, aumentou o número de brotações na concentração de 4,67 mg L-1 de BAP, o que também possibilitou aumento da biomassa seca.

As concentrações de BAP mostraram ter efeito negativo para a formação de raízes, independente da posição do explante. Apenas houve

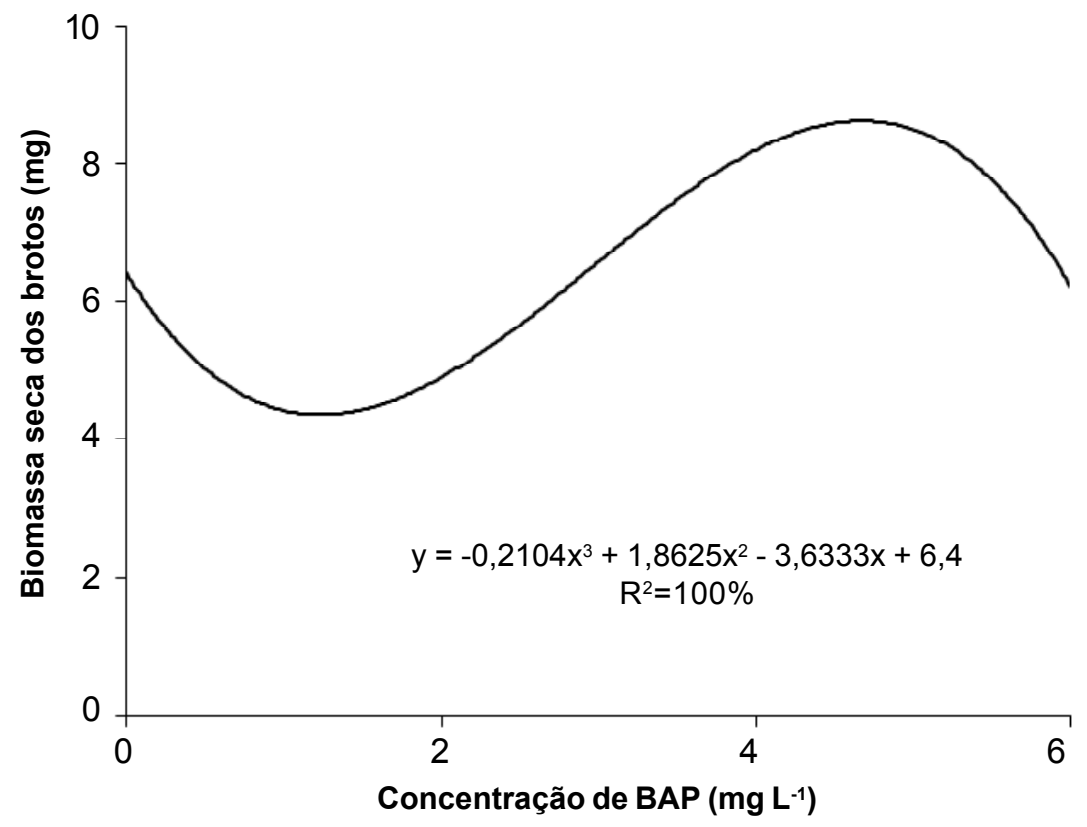

FIGURA 4. Biomassa seca dos brotos de O. selloi submetidas a diferentes concentrações de BAP, aos 30 dias de cultivo in vitro em meio MS.

formação de raízes na ausência do BAP, sendo este o melhor tratamento para o número, o comprimento e a biomassa fresca e seca de raízes. A diminuição da produção de raízes com a adição de BAP normalmente ocorre porque esse regulador é inibidor do sistema radicular, e a indução ou a inibição dependerão do balanço e da interação entre as substâncias de crescimento endógenas e exógenas. Santana et al. (2006), trabalhando com O. basilicum, demonstraram que, para a variável porcentagem de raízes, os meios de cultivo sem BAP e nas concentrações de 2 a $4 \mathrm{mg} \mathrm{L}^{-1}$ apresentaram os maiores valores. Segundo a mesma autora, a medida em que as concentrações do regulador de crescimento aumentaram, a porcentagem de raízes tendeu a diminuir.

Conclui-se que nas condições testadas, recomenda-se o uso do primeiro e segundo segmento nodal suplementando o meio de cultivo com BAP para a proliferação in vitro de brotações de $O$. selloi.

\section{AGRADECIMENTO}

Os autores agradecem ao Conselho Nacional de Desenvolvimento Científico e Tecnológico (CNPq), a Coordenação de Aperfeiçoamento de Pessoal de Nível Superior (CAPES) e a Fundação de Amparo à Pesquisa do Estado de Minas Gerais (FAPEMIG) pela concessão de bolsas de estudos e suporte financeiro à pesquisa. 


\section{REFERÊNCIA}

AMARAL, C.L.F. et al. Indução de organogênese em alfavaca (Ocimum selloi Benth.) cultivados in vitro: efeito da posição dos explantes e dos agentes gelificantes do meio. Diálogo e Ciências, n.12, p.1-8, 2007.

BRUM, G.R. et al. Efeito de diferentes concentrações de BAP e ANA na propagação in vitro da figueira (Ficus carica L.). Ciência Agrotécnica, v.26, n.2, p.1403-9, 2002. CAMPOS, R.A.S. et al. Micropropagação de Jatropha elliptica (Pohl) Müll. Arg. Revista Brasileira de Plantas Medicinais, v.9, n.3, p.30-6, 2007.

DODE, L.B. et al. In vitro propagation of Ocimum basilicum L. (Lamiaceae). Acta Scientiarum Biological Sciences, v.25, n.2, p.435-7, 2003.

FERREIRA, D.F. SISVAR: sistema de análise de variância versão 5.0. Lavras: Departamento de Ciências Exatas, 2007.

FRANCA, C.S. et al. Analgesic and antidiarrheal properties of Ocimum selloi essential oil in mice. Fitoterapia, v.79, p.569-73, 2008.

LESHEM, B. et al. The effect of cytokinins on vitrification in melon and carnation. Annals of Botany, v.62, p.271-6, 1988.

LORENZI, H.E.; MATOS, F.J.A. Plantas medicinais no Brasil: nativas e exóticas. Nova Odessa: Instituto Plantarum, 2002. 512p.

MURASHIGE, T.; SKOOG, F. A revised medium for rapid growth and bioassays with tobacco tissue cultures. Physiologia Plantarum, v.15, n.3, p.473-97, 1962.

PEREIRA, J.E.S. et al. Influência do número de gemas, presença ou ausência de folhas e posição do explante na multiplicação in vitro de batata. Horticultura Brasileira, v.23, n.1, p.86-9, 2008.

PÉREZ-TORNERO, O. et al. Effect of basal media and growth regulators on the in vitro propagation of apricot (Prunus armenica L.) cv. Canino. Journal of Horticultural Science \& Biotechnology, v.75, p.283-6, 2000.

POOVAIAH, C.R. et al. Adventitious shoot regeneration of scotch spearmint (Mentha x gracilis Sole). In Vitro Cellular and Developmental Biology-Plant, n.42, p.354-8, 2006a. POOVAIAH, C.R. et al. In vitro adventitious shoot regeneration of native spearmint using internodal explant. HortScience, v.41, n.2, p.414-17, 2006b.

REIS, E.S. et al. Influência do meio de cultura na germinação de sementes in vitro e taxa de multiplicação de Melissa officinalis L. Revista Ceres, v.55, p.160-7, 2008. REIS, E.S. et al. Teor e composição química do óleo essencial de Melissa officinalis L. in vitro sob influência do meio de cultura. Acta Scientiarum, v.31, p.331-5, 2009. ROSAL, L.F. et al. Micropropagation of the medicinal plant Eremanthus erythropappus (DC.) MacLeish. HortScience, v.42, n.6, p.1420-4, 2007.

SANTANA, J.G.S. et al. Influência de concentrações de BAP na micropropagação de manjericão (Ocimum basilicum L. NSL6421-S2-05). In: CONGRESSO BRASILEIRO DE OLERICULTURA, 46., 2006, Goiânia. Horticultura Brasileira, v.24, p.2625-8, 2006.

SOUZA, A.V. et al. In vitro propagation of Lychnophora pinaster (Asteraceae): a threatened endemic medicinal plant. HortScience, v.42, n.7, p.1665-9, 2007.

TAIZ, L.; ZEIGER, E. Fisiologia vegetal. 3.ed. Porto Alegre: Artmed, 2004. 719p.

VICENTE, M.A.A. et al. Multiplicação in vitro e aclimatação de Vernonia condensata Baker. Revista Brasileira de Plantas Medicinais, v.11, n.2, p.176-83, 2009.

WANG, X. et al. Highly efficient in vitro adventitious shoot regeneration of peppermint (Mentha piperita L.) using internodal explants. In Vitro Cellular and Developmental Biology-Plant, v.45, p.435-40, 2009. 